\title{
Hypothalamic-pituitary-gonadal axis in two men with aromatase deficiency: evidence that circulating estrogens are required at the hypothalamic level for the integrity of gonadotropin negative feedback
}

\author{
Vincenzo Rochira $^{1, *}$, Lucia Zirilli ${ }^{1, *}$, Alessandro D Genazzani ${ }^{2}$, Antonio Balestrieri $^{1}$, Claudio Aranda ${ }^{4}$, \\ Bibiana Fabre ${ }^{4}$, Paula Antunez ${ }^{3}$, Chiara Diazzi ${ }^{1}$, Cesare Carani ${ }^{1}$ and Laura Maffei ${ }^{3}$ \\ ${ }^{1}$ Integrated Department of Medicine, Endocrinology, Metabolism and Geriatrics and ${ }^{2}$ Department of Obstetrics and Gynecology, University of Modena and \\ Reggio Emilia, Via Giardini 1355, 41100 Modena, Italy, ${ }^{3}$ Consultorios Asociados de Endocrinologia, Buenos Aires, Argentina and ${ }^{4}$ Tomografia \\ Computada Buenos Aires-TCBA, Buenos Aires, Argentina
}

(Correspondence should be addressed to C Carani; Email: carani.cesare@unimore.it)

*(V Rochira and L Zirilli contributed equally to this work)

\begin{abstract}
Background: In men, the feedback of gonadotropins is regulated by estrogens that come from the aromatization of testosterone, but the relative contribution to the inhibition of LH and FSH secretion by the amount of locally produced estrogens within the hypothalamus and/or the pituitary, and the amount of circulating estrogens still remains unknown.

Objective: In order to evaluate the effect of regulation induced by estradiol on the hypothalamicpituitary-gonadal (HPG) axis, we studied the pulsatility of LH and FSH in two aromatase-deficient men (called subject 1 and subject 2), in which the production rate of estrogen (both local and circulating) is completely, or at least severely, impaired.

Design: FSH and LH were evaluated in terms of their pulsated secretion and as GnRH-stimulated secretion in two phases: phase 1, before estrogen treatment; and phase 2, during estrogen treatment with $25 \mu \mathrm{g}$ transdermal estradiol twice weekly.

Methods: Blood samples were taken during phase 1 and phase 2 at $0800 \mathrm{~h}$ for basal measurements of LH, FSH, inhibin B, testosterone, and estradiol. The analysis of the pulsatility of LH and FSH was performed by sampling every $10 \mathrm{~min}$ for $8 \mathrm{~h}$ in the two phases. Gonadotropin response to GnRH-stimulation test was studied by serial standard sampling after $100 \mu \mathrm{g}$ GnRH i.v. bolus in phases 1 and 2 .

Results: Estrogen treatment led to a significant reduction in both LH-pulsated frequency $(7.5 \pm 0.7$ in phase $1,4.5 \pm 0.7$ in phase 2$)$ and amplitudes $(3.5 \pm 0.006$ in phase $1,1.9 \pm 0.4$ in phase 2$)$ of peaks, whereas FSH showed only a conspicuous reduction in serum levels and a trend towards the reduction of the amplitudes of its peaks without modification of the frequency of the pulses. Both testosterone and gonadotropins decreased during phase 2 , whereas estradiol reached the normal range in both subjects. Transdermal estradiol treatment significantly lowered the peaks of both serum LH and FSH after GnRH as well as the incremental area under the curve after GnRH administration in both subjects. Basal serum inhibin B levels were slightly higher before transdermal estradiol treatment (phase 1) than during estrogen treatment (phase 2) in both subjects.

Conclusions: The administration of estrogen to aromatase-deficient men discloses the effects of circulating estrogens on LH secretion, exerted both at pituitary level, as shown by the decrease of basal and GnRH-stimulated secretion of LH and the LH pulsed amplitude, and at hypothalamic level as shown by the reduction of the frequency of LH pulses. The present study, coupling the outcomes of basal, GnRH-stimulated and the pulsatile evaluation of LH and FSH secretion in two aromatase-deficient men, demonstrates that circulating estrogens play an inhibitory role in LH secretion by acting on the hypothalamus and the pituitary gland of men. The discrepancy among testosterone levels, the arrest of spermatogenesis and a slightly inappropriate respective increase of serum FSH (lower than expected) suggests a possible role of estrogens in the priming and the maturation of HPG axis in men, an event that has never occurred in these two subjects as a consequence of chronic estrogen deprivation.
\end{abstract}

European Journal of Endocrinology 155 513-522 


\section{Introduction}

The regulation of the feedback of luteinizing hormone (LH) and follicle-stimulating hormone (FSH) in men is, in part, under the control of estrogen and requires an adequate amount of estradiol that comes from the aromatization of testosterone $(1,2)$. Exogenous estradiol significantly decreases the mean circulating LH and FSH levels as well as the amplitude of LH pulses when administered both to normal men and male patients affected by isolated gonadotropin-releasing hormone (GnRH) deficiency, but under long-term pulsatile GnRH replacement therapy (2). These data clearly demonstrate a direct modulatory and inhibitory effect of estradiol on the pituitary release and/or synthesis of LH and FSH in normal and GnRH-deficient men $(1,2)$. In the 1990s, Bagatell et al. provided indirect evidence of the need of aromatization of androgen for a normal function of the feedback of gonadotropins (3) by inducing the suppression of gonadotropins, both with testosterone or estradiol infusion in men affected by idiopathic hypothalamic hypogonadism (IHH). Conversely, they did not record any change in LH and FSH secretion when a pure androgen molecule like dihydrotestosterone (DHT) was administered. These data indirectly suggest that the peripheral $5 \alpha$-reduction of testosterone to DHT plays a minor role on the control of the secretion of gonadotropins (3). Thus, a great part, if not all, of the inhibitory effect on gonadotropin secretion is mediated by the endogenous conversion of testosterone to estradiol at the pituitary level rather than direct androgen action (Fig. 1). Several subsequent studies performed by Veldhuis and colleagues suggested that in situ aromatization of testosterone is required both at hypothalamic and pituitary levels to guarantee a normal functioning of the feedback of gonadotropins $(4,5)$. In addition, they also postulated a role for circulating estrogens in the control of gonadotropin feedback, but only at pituitary level (5) (Fig. 1). At present, this represents the prevailing view among physicians (1-5).

The hypothalamic site of the action of estrogens has been demonstrated only recently in men by Hayes and colleagues, who compared healthy men taking a selective aromatase inhibitor (anastrozole) with men with IHH whose gonadotropic secretion had previously been normalized by long-term pulsatile GnRH therapy (6). Anastrozole led to the inhibition of estradiol synthesis and, consequently, a corresponding increase in mean levels of LH and FSH, both in normal and IHH men. Interestingly, the major increase was observed in normal subjects compared with men affected by IHH and also involved the frequency and amplitude of LH pulses (6). Such observations suggest that the aromatase inhibitor was more effective on the intact hypothalamus, thus supporting the hypothesis of a possible hypothalamic site of action for estrogens. In this view, novelty is represented by the idea that estrogens would exert their modulating action on gonadotropin secretion both at pituitary and hypothalamic level in the human male (6) (Fig. 1). Estrogen action on the hypothalamus has subsequently been confirmed in normal healthy men after pharmacologically-induced hypogonadism (5). Further evidence suggests that aromatization of estrogens may be required at the pituitary level for the control of gonadotropin feedback through men's life (7-10). In fact, anastrozole lowered serum estradiol in young men aged $14-22$ years, with a

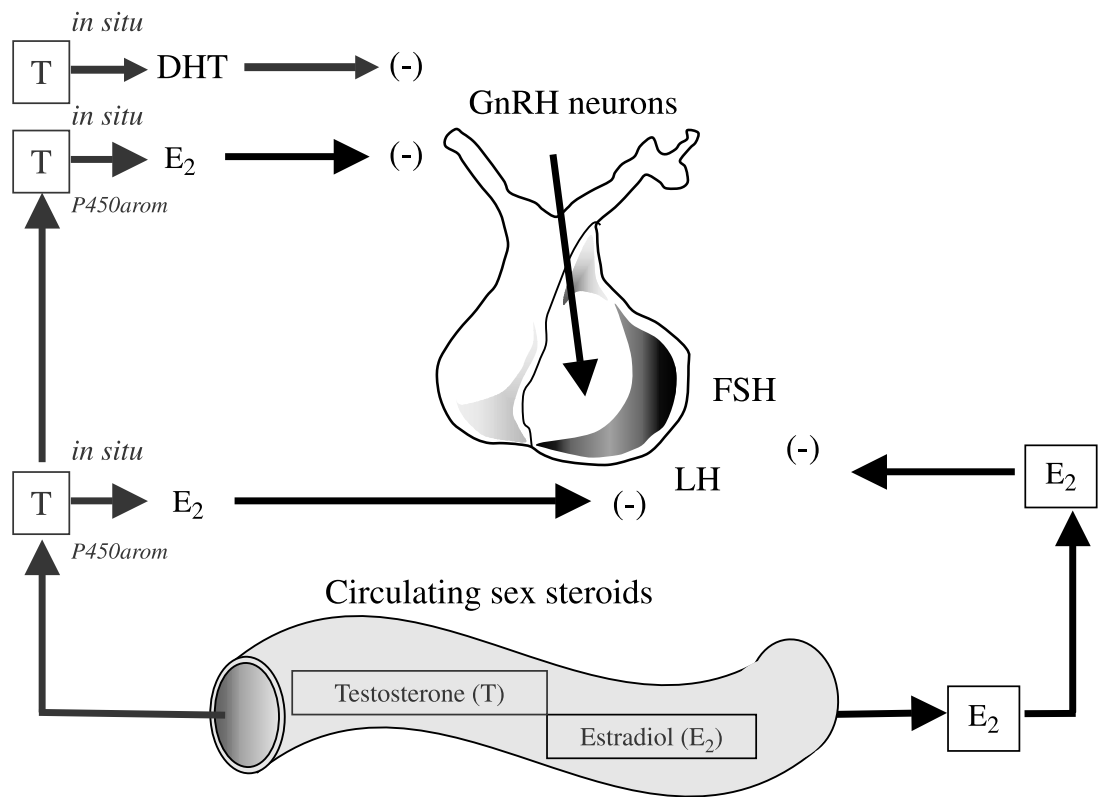

Figure 1 Scheme of hypothalamic-pituitary-gonadal (HPG) axis control exerted by both circulating and in situ locally produced estradiol in men. DHT, dihydrotestosterone; $\mathrm{GnRH}$, gonadotropin-releasing hormone; $\mathrm{LH}$, luteinizing hormone; $\mathrm{FSH}$, follicle-stimulating hormone; P450arom, aromatase enzyme. 
concomitant increase of both serum gonadotropins and testosterone concentrations (7). Furthermore, in the early and mid-pubertal phases, the administration of letrozole, another potent aromatase inhibitor, raised basal serum LH, the frequency and amplitude of LH pulses and the response of $\mathrm{LH}$ to a GnRH bolus, thus indicating that estrogens act at the pituitary level during the early phases of pubertal maturation (8). The same estrogen-related mechanism seems to operate even in adulthood and senescence (9), particularly on LH modulation in older men $(9,10)$.

Since 1994, several cases of congenital estrogen deficiency have been described $(11,12)$ and have helped to highlight the relationship between the lack of estrogen production (13-15) or activity (16), and gonadotropin feedback in men, but have left some aspects unsolved (17). In particular, it is not yet understood in detail what the relative contribution to gonadotropin feedback of estrogens locally produced within both the hypothalamus and the pituitary, and/or that of circulating estrogens is $(5,17)$. It remains to be ascertained whether, at the hypothalamic and the pituitary level in men, the action of estrogens are genomic or non-genomic and which receptors $(\alpha$ or $\beta$ ) are involved in the transduction of the biochemical signal (17).

The aim of this study was to evaluate the effects of estradiol administration on the secretion of $\mathrm{LH}$ in two adult men with aromatase deficiency who represent a human model of a congenital lack of estrogen. The novelty of the study is represented by the evaluation of the effects of estradiol also on LH pulsatility being based on both basal $(13,14)$ and stimulated (15) LH levels previously described at least in part. The study was also extended to FSH secretion, bearing in mind that the concomitant severe impairment of spermatogenesis in both subjects constitutes a confounding factor. In particular, we studied the effects of estradiol administration on pulsated LH and FSH secretion by analysis of the amplitude and frequency of their peaks in order to disclose the effects of circulating estrogens on hypothalamic-pituitary feedback in the unique human in vivo model of estrogen deficiency in which the production of estrogen (both local and circulating) is severely impaired. This model of investigation is complementary to those study protocols previously mentioned in which estrogen suppression is limited by the potency of the drugs administered (aromatase inhibitors) (5-10) or the presence of an intact enzyme pathway of androgen conversion into estradiol, as in normal or IHH men $(1-4,6)$.

\section{Subjects and methods}

This study has been performed in two subjects affected by aromatase deficiency whose clinical and genetical aspects have been already published $(13,14,18)$. Subject 1 is referred to as the aromatase-deficient man described by Carani et al. in 1997 (13) and subject 2 is the one described by Maffei, Carani et al., in 2004 (14). Both subjects were treated with transdermal estradiol $25 \mu \mathrm{g}$ twice weekly. The study design is reported in Figure 2. In the tables and figures we remarked some of the data already published elsewhere (13-15, 18).

The effect of estradiol on hypothalamic-pituitarygonadal (HPG) axis was prospectively studied in the two subjects before (phase 1) and during (phase 2) estradiol administration (Fig. 2). A treatment with transdermal estradiol $25 \mu \mathrm{g}$ twice weekly was performed for at least 6 months in each of the two subjects; the results of the GnRH test in subject 1 have already been published (15). As far as subject 1 is concerned, the patient, after giving his informed consent to the treatment was reassessed after a wash-out period of 3 months from a previous estrogen treatment (phase 1) (15) and after 9 months of transdermal estradiol treatment (Estraderm, patch system) at the dose of $25 \mu \mathrm{g}$ twice weekly (phase 2) (15). As far as subject 2 is concerned, the patient was assessed at the time of diagnosis of aromatase deficiency after a period of 9 months wash-out from previous treatments with androgens (phase 1) (14) and after 6 months of transdermal estradiol (Estraderm, patch system) at the dose of $25 \mu \mathrm{g}$ twice weekly (phase 2) (14).

The study was performed for subject 1 at the Endocrine Unit of the Integrated Department of Medicine, Endocrinology, Metabolism and Geriatrics University of Modena and Reggio Emilia, and for subject 2 at the Consultorios Asociados de Endocrinologia of Buenos

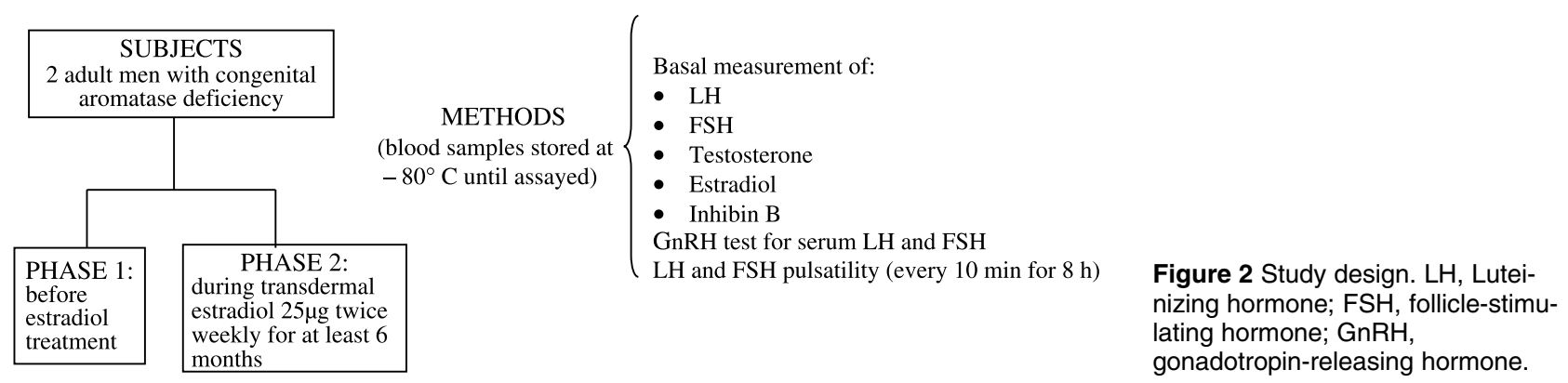


Aires, Argentina. Serum samples of both men were stored separately, but were subsequently assayed at the Endocrine Unit of the University of Modena and Reggio Emilia. Both subjects provided written informed consent to both treatment and publication of data. The study was approved by the local ethical committee.

\section{Assessment of HPG function}

Basal measurements Serum measurements were obtained after the collection of blood basal samples during phases 1 and 2 (Fig. 2) and samples were stored until basal determination of estradiol, testosterone, inhibin B, LH, and FSH levels.

Dynamic test A GnRH test was performed at $0800 \mathrm{~h}$ after on overnight fast during each phase (Fig. 2). LH and FSH serum levels were measured after GnRH infusion (100 $\mu$ g i.v. Gonadorelin, Ferring) with blood sampling at $-15,0,30,45,60$, and $90 \mathrm{~min}$. All blood samples were collected during GnRH testing in both phases 1 and 2 and stored until assayed.

Gonadotropin pulsatile secretion The study was designed in order to evaluate LH and FSH pulsatility during phases 1 and 2 in both subjects. They were admitted at the respective Endocrine Units at $0800 \mathrm{~h}$ after an overnight fast for the evaluation of LH and FSH pulsatility. A venous catheter was placed into a forearm vein before pulsatility assessment until $1600 \mathrm{~h}$, after which subjects were discharged. The following blood samples were collected every $10 \mathrm{~min}$ for $8 \mathrm{~h}(49$ samples) from 0800 to $1600 \mathrm{~h}$ in order to determine the spontaneous episodic LH and FSH secretion as previously described (19). In the 8-h blood sampling, all the samples obtained were stored until assayed for $\mathrm{LH}$ and FSH.

\section{Hormonal measurements}

All serum samples were stored at $-80^{\circ} \mathrm{C}$ until assayed. $\mathrm{FSH}, \mathrm{LH}$, testosterone, and estradiol of the two men were assayed in the laboratory at the Unit of Endocrinology of the University of Modena and Reggio Emilia.

Serum LH and FSH were measured using a fluoroimmunoassay (Autodelfia hLH kit, Wallac, Oy, Turku, Finland) with a sensitivity of $0.05 \mathrm{mIU} / \mathrm{l}$. The inter- and the intraassay coefficients of variation $(\mathrm{CV})$ were 3.6 and $2.8 \%$, for LH and 4.1 and $2.6 \%$ respectively for FSH.

Serum total testosterone was measured using commercial RIA (Diagnostic product corp., Los Angeles, CA, USA). The inter- and the intraassay $\mathrm{CV}$ values for testosterone were 11 and 5\% respectively.

Serum estradiol was detected using a commercially available double antibody RIA (Third-Generation
DSL-39 100, Diagnostic Systems Laboratories, Inc., Webster, TX). Sensitivity was $0.6 \mathrm{pg} / \mathrm{ml}(2.2 \mathrm{pmol} / \mathrm{l})$ with the lowest standard at $1.5 \mathrm{pg} / \mathrm{ml}(5.5 \mathrm{pmol} / \mathrm{l})$, linearity to $150 \mathrm{pg} / \mathrm{ml}(550 \mathrm{pmol} / \mathrm{l})$, and an ED50 of $20 \mathrm{pg} / \mathrm{ml}(73 \mathrm{pmol} / \mathrm{l})$. The cross-reactivity with estrone and less potent estrogens was less than 7 and $0.45 \%$ respectively. The inter- and the intraassay $\mathrm{CV}$ values for estradiol were 4.1-9.9 and 3.4-3.9\% respectively.

Serum inhibin B was measured by a two-site ELISA (Serotec, Kidlington, UK) with a sensitivity of $15 \mathrm{pg} / \mathrm{ml}$. The inter- and intraassay CV values were less than $10 \%$. The cross-reactivity with inhibin A was 0.85 .

\section{Statistical analysis}

Time series of LH and FSH were first evaluated separately to estimate the random measurement error on the duplicates using the program PREDETEC.WK1 as previously described (19-21). Then secretory episodes on each time series were identified using the program DETECT as previously described (21) with a $P$ value equal to 0.01 ( $1 \%)$ for the nominal falsepositive rate.

We also tested for significant differences between groups, after one-way ANOVA, using Student's $t$-test for paired data. Data are expressed as mean \pm s.D.

\section{Results}

\section{Gonadotropin pulsated secretion}

In phase 1 , the frequency of LH and FSH pulses as well as mean integrated levels of both gonadotropins were slightly above the values obtained in normal men (22-24), while the amplitude of pulses of LH and FSH were normal. Estrogen treatment modified the episodic secretion of LH. A significant reduction in the frequency and amplitude of LH pulses was observed in each subject (Fig. 3a and b), and consequently also the mean of the LH-integrated levels of both subjects when pooled together were significantly reduced (computed on the data of each pulsatility) (Table 1). Accordingly, the mean of the pooled FSH-integrated level of both subjects was markedly reduced during estrogen treatment (Table 1). Conversely, the analysis of FSH pulses did not reveal any modification of frequency, while a trend for a reduction of the amplitude of pulses was recorded, although not significant $(P<0.2)$ (Table 1).

\section{Dynamic test}

A normal to higher LH response to i.v. GnRH bolus and a normal FSH response to i.v. GnRH bolus were observed during both phases of the study (25). Transdermal estradiol treatment significantly lowered the peaks of 

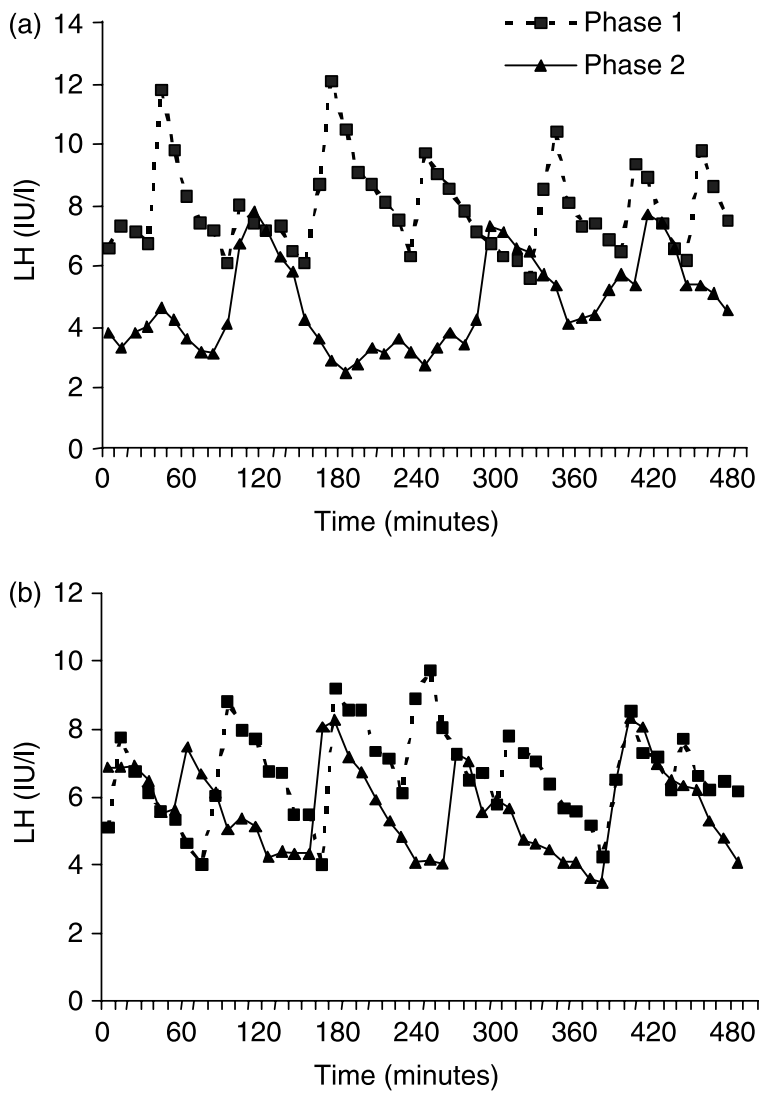

Figure 3 Luteinizing hormone (LH) episodic secretion before and under estradiol (E2) administration of subjects 1 (3a) and 2 (3b) before estrogen treatment (phase 1, dot line) and during transdermal E2 $25 \mu \mathrm{g}$ twice weekly (phase 2, dot line).

both serum LH (Fig. 4a) and FSH (Fig. 4b) after exogenous GnRH as well as the incremental area under the curve after GnRH administration in both subjects (Fig. 4). The results of GnRH test of subject 1 have already been reported (15).

\section{Basal measurements}

In phase 1, basal serum FSH of both subjects was higher than normal, whereas LH was slightly above the normal range (Table 2). In phase 2, during estradiol treatment, testosterone decreased and estradiol levels reached the normal values for an adult man (Table 2), while serum LH, and FSH levels decreased, but FSH did not reach the value close to normality in both subjects and remained below the value of $11 \mathrm{IU} / \mathrm{l}$ (Table 2). Basal serum inhibin B levels were slightly higher before transdermal estradiol treatment (phase 1) than during estrogen treatment (phase 2) in both subjects. Subject 2 showed a lower serum inhibin B level than subject 1 (Table 2). In particular, the inhibin $\mathrm{B}$ to $\mathrm{FSH}$ ratio remained constantly less than the value of 10 in both subjects in phases 1 and 2 (Table 2). The results of basal measurements have already been reported $(13-15,18)$.

\section{Discussion}

The present investigation discloses the inhibitory role of estrogens on the secretion of gonadotropins by coupling the outcomes coming from the analysis of GnRHstimulated secretion and the pulsated secretion of LH and FSH in two men with aromatase deficiency. Even though the number of subjects is small, these data are complementary to the results previously obtained in this rare disease from both basal measurements $(13,14,16$, $18,26-28)$ and secretion of gonadotropins induced by exogenous GnRH $(15,28)$ (reviews; 11, 12, 29).

As far as the pulsatility study is concerned, the interval of the blood sampling is short and limited to only $8 \mathrm{~h}$, but the observed changes of LH pulses, coupled with this unique in vivo model of pure severe chronic estrogen deficiency (both circulating and locally produced estrogens) allows us to make some important considerations on the relationships between the estrogen (particularly the circulating quote) and hypothalamic function. The present clinical

Table 1 Pulsatility of gonadotropin: luteinizing hormone (LH) and follicle-stimulating hormone (FSH) levels, LH and FSH pulse frequency and LH and FSH pulse amplitude before and during transdermal estradiol treatment in the two subjects with aromatase deficiency. Data are expressed as mean \pm s.D.

\begin{tabular}{|c|c|c|c|}
\hline & $\begin{array}{l}\text { Mean integrated LH level } \\
(\mathrm{mlU} / \mathrm{ml})\end{array}$ & LH pulses/8 h & LH pulse amplitude (mIU/ml) \\
\hline \multirow[t]{2}{*}{$\begin{array}{l}\text { Phase } 1 \\
\text { Phase } 2 \\
\text { Normal control values }^{\mathrm{a}}\end{array}$} & $\begin{array}{l}7.3 \pm 0.8 \\
5.2 \pm 0.6^{\star} \\
0.2-6.5\end{array}$ & $\begin{array}{l}7.5 \pm 0.7 \\
4.5 \pm 0.7^{\dagger} \\
4-6\end{array}$ & $\begin{array}{l}3.5 \pm 0.06 \\
1.9 \pm 0.4^{\dagger} \\
1.5-4\end{array}$ \\
\hline & $\begin{array}{c}\text { Mean integrated FSH level } \\
(\mathrm{mlU} / \mathrm{ml})\end{array}$ & FSH pulses/8 h & FSH pulse amplitude $(\mathrm{mlU} / \mathrm{ml})$ \\
\hline $\begin{array}{l}\text { Phase } 1 \\
\text { Phase } 2 \\
\text { Normal control values }\end{array}$ & $\begin{array}{c}22.835 \pm 3.52^{*} \\
10.505 \pm 1.18^{*} \\
0.5-8\end{array}$ & $\begin{array}{l}7.5 \pm 2.12 \\
7.5 \pm 0.7 \\
4-6\end{array}$ & $\begin{array}{l}2.335 \pm 0.37^{\ddagger} \\
1.715 \pm 0.6 \\
\quad 1.5-5\end{array}$ \\
\hline
\end{tabular}

${ }^{\star} P<0.05 ;{ }^{\dagger} P<0.02 ;{ }^{\ddagger} P<0.2$.

${ }^{a}$ Normal control values refer to studies of gonadotropin secretion in normal men (22-24). 

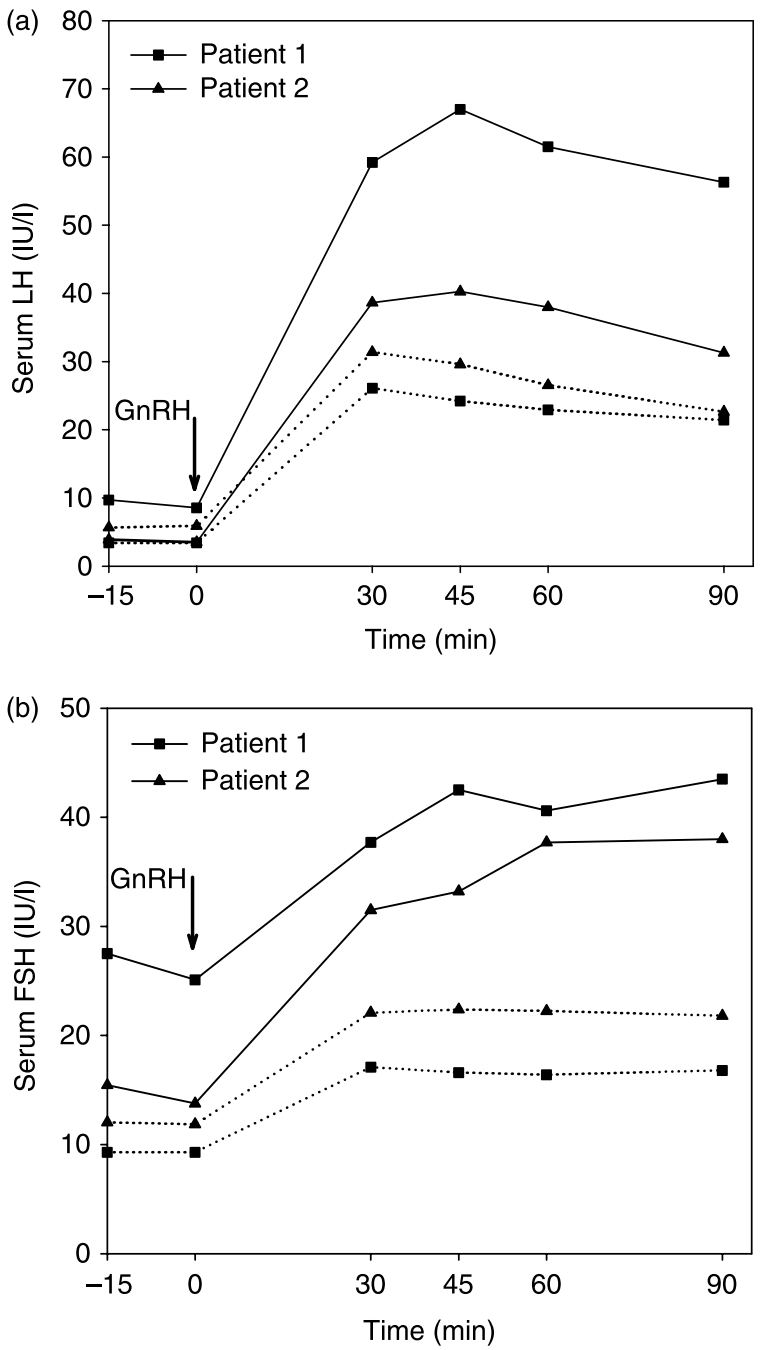

Figure 4 Serum luteinizing hormone (LH) $(A)$ and follicle-stimulating hormone ( $\mathrm{FSH})(\mathrm{B})$ levels after exogenous gonadotropin-releasing hormone $(\mathrm{GnRH})(100 \mu \mathrm{g}$ i.v.) before transdermal estradiol treatment (phase 1) and during transdermal estradiol treatment $25 \mu \mathrm{g}$ twice weekly (phase 2). A two- to five-fold rise in serum LH and a one- to two-fold rise in serum FSH are considered as a normal response to $\mathrm{GnRH}$ stimulation (25). Subject 1, $\mathbf{\square}$; subject 2, $\mathbf{\Delta}$; solid line for phase 1; dotted line for phase 2. LH and FSH after $\mathrm{GnRH}$ infusion of subject 1 have been already published (13).

investigation tests the hypothesis that circulating estradiol may be involved in the control of estrogendependent negative feedback by modulating the pattern of pulsatile LH release. The results of previous studies were obtained by acute pharmacological suppression of estrogens (5-10), while the outcome of the present study also accounts for early (fetal and perinatal) severe estrogen depletion. The restoration of normal circulating estradiol levels by exogenous administration of transdermal estradiol (phase 2) led to a marked reduction in the frequency of LH pulses in both subjects, suggesting a putative modulatory role for serum estradiol in the hypothalamus in the human male. Accordingly, the amount of estradiol in serum seems to be determinant for the control of LH pulse frequency. The increase in circulating estradiol and the restoration of normal circulating estradiol levels in these two aromatase-deficient men in whom the local production of estrogen is severely impaired is able to modify the frequency of LH pulses and therefore hypothalamic function. Thus, circulating estradiol probably suppresses the endogenous GnRH secretion by modulating the activity of GnRH neurons at hypothalamic levels. This implies that the hypothalamic gonadostat is sensitive to circulating estradiol in adult men and its regulation is not just under the effect of estrogens locally produced within the hypothalamus (Fig. 5). This mechanism of estrogen action is coupled to the wellknown in situ aromatization of testosterone within the hypothalamus, both operating in normal, $\operatorname{IHH}(5,6)$, and agonadal men receiving testosterone replacement (30). The responsiveness of the hypothalamus to circulating estradiol suggests that the quote of serum estradiol could be quantitatively more relevant in vivo in controlling the feedback of LH with respect to locally produced estrogens (Fig. 5), since serum estradiol represents a greater source of estrogen than that produced in situ within the hypothalamus.

The analysis of the GnRH-stimulated gonadotropin secretion showed a significant reduction of both LH and FSH peaks, as well as the area under the curve during transdermal estradiol treatment in both subjects. These results fit the data obtained in another aromatasedeficient man under GnRH stimulation (28) and have been published, at least in part, as far as subject 1 is concerned (15). This result confirms that circulating estrogens act within the pituitary (Figs 1 and 5) through the modulation of the release of the pituitary reserve of gonadotropins in response to exogenous GnRH, also in the absence of a local production of estrogens. This has been previously suggested by Schnorr and colleagues in their model of HPG axis functioning (5). Accordingly, the analysis of the pulsatility pattern demonstrated a reduction of the amplitude of LH peaks during transdermal estradiol treatment (phase 1 versus phase 2) (Table 1), implying that estrogens modulate the sensitivity of the pituitary also to endogenous GnRH. Thus, data obtained from both endogenous and exogenous stimulation of pituitary function show an inhibitory control exerted by circulating estrogens, which seems to act in a dose-dependent fashion at the pituitary level (15). A dose-dependent reduction of gonadotropins in response to exogenous estradiol administration, in fact, is also seen in male to female transsexuals treated with high doses of estrogen (31) as well as in men with congenital estrogen excess (32). In parallel, data obtained from boys $(7,8)$, adults $(5,7)$, and older men $(9,10)$ taking an aromatase inhibitor, show a corresponding increase in serum gonadotropins according to the dosage of the drug.

Basal hormone measurements, although already published, are useful for a better comprehension of 
Table 2 Basal testosterone, estradiol and gonadotropins serum levels before (phase 1) and during transdermal estradiol treatment (phase 2). Data are expressed in Conventional Units; SI values are in parentheses.

\begin{tabular}{|c|c|c|c|c|}
\hline Serum hormones & Normal values & Subjects & Phase 1 & Phase 2 \\
\hline Testosterone & $3.6-9 \mathrm{ng} / \mathrm{ml}(12.5-31 \mathrm{nmol} / \mathrm{l})$ & $\begin{array}{l}\text { Subject } 1 \\
\text { Subject } 2\end{array}$ & $\begin{array}{l}5.2^{\mathrm{a}, \mathrm{b}}(18.0 \mathrm{nmol} / \mathrm{l}) \\
2.7^{\mathrm{d}}(9.4 \mathrm{nmo} / \mathrm{l})\end{array}$ & $\begin{array}{l}4.2^{\mathrm{b}, \mathrm{c}}(14.5 \mathrm{nmol} / \mathrm{l}) \\
1.45^{\mathrm{d}}(5.0 \mathrm{nmol} / \mathrm{l})\end{array}$ \\
\hline Estradiol & $10-40 \mathrm{pg} / \mathrm{ml}(36.7-146.9 \mathrm{pmol} / \mathrm{l})$ & $\begin{array}{l}\text { Subject } 1 \\
\text { Subject } 2\end{array}$ & $\begin{array}{l}<1.5^{\mathrm{a}, \mathrm{b}, \mathrm{c}}(<5.5 \mathrm{pmol} / \mathrm{l}) \\
<1.5^{\mathrm{d}}(<5.5 \mathrm{pmol} / \mathrm{l})\end{array}$ & $\begin{array}{l}24^{\mathrm{b}, \mathrm{c}}(88 \mathrm{pmol} / \mathrm{l}) \\
23.5^{\mathrm{d}}(86.23 \mathrm{pmol} / \mathrm{l})\end{array}$ \\
\hline LH & $0.2-6.5 \mathrm{mlU} / \mathrm{ml}$ & $\begin{array}{l}\text { Subject } 1 \\
\text { Subject } 2\end{array}$ & $\begin{array}{l}9.7^{\mathrm{c}} \\
7^{\mathrm{d}}\end{array}$ & $\begin{array}{l}3.1^{\mathrm{c}} \\
5.9^{\mathrm{d}}\end{array}$ \\
\hline $\mathrm{FSH}$ & $0.5-8 \mathrm{mlU} / \mathrm{ml}$ & $\begin{array}{l}\text { Subject } 1 \\
\text { Subject } 2\end{array}$ & $\begin{array}{l}27.5^{c} \\
20^{d}\end{array}$ & $\begin{array}{l}9.3^{c} \\
10.5^{d}\end{array}$ \\
\hline Inhibin B & $100-400 \mathrm{pg} / \mathrm{ml}$ & $\begin{array}{l}\text { Subject } 1 \\
\text { Subject } 2\end{array}$ & $\begin{array}{l}113^{c} \\
68\end{array}$ & $\begin{array}{l}70.1^{c} \\
58\end{array}$ \\
\hline Inhibin $\mathrm{B} / \mathrm{FSH}$ ratio & - & $\begin{array}{l}\text { Subject } 1 \\
\text { Subject } 2\end{array}$ & $\begin{array}{l}4.1 \\
3.4\end{array}$ & $\begin{array}{l}7.5 \\
5.5\end{array}$ \\
\hline
\end{tabular}

$\mathrm{LH}$, luteinizing hormone; FSH, follicle-stimulating hormone.

a'Data already published by Carani et al. (11).

${ }^{b}$ Data already published by Rochira et al. (16).

'Data already published by Rochira et al. (13).

dData already published by Maffei et al. (12).

this issue. These two subjects $(13,14)$ and other adult men with aromatase deficiency $(12,26-29)$ share the same pattern of basal serum hormones; elevated FSH, heterogeneous values of both basal serum LH (varying from upper-normal to high values), testosterone (ranging from low or normal-to-high levels), and undetectable serum estradiol (12-14, 26-28). Elevated levels of gonadotropins, coupled with a wide variability in serum testosterone in these patients, demonstrate that testosterone alone cannot induce the inhibitory effect on gonadotropins at the pituitary level $(12,17$, 29 ), as confirmed by the lack of changes in serum LH and FSH even during high dose testosterone treatment in subject 1 (13). Conversely, estradiol-replacement treatment is able to reduce basal LH and FSH and restore, at least in part, a normal function of the feedback of gonadotropins in aromatase-deficient men $(13-15,18,27,28)$.
The lack of significant modification of FSH pulses during estradiol treatment in the two subjects seems to be discordant with previous reports suggesting that the aromatization is much more involved in the control of FSH rather than LH secretion $(5,33)$. Probably, the concomitant dysfunction of spermatogenesis in these two subjects represents a confounding factor. Thus, even if the integrated mean FSH levels were lowered and a trend for the reduction of the amplitude of FSH pulses has been recorded during estradiol treatment, a great part of the effect of estrogen on FSH secretion is masked by the severe impairment of spermatogenesis $(11,13$, 15). In addition, a complete normalization of serum FSH during estradiol treatment was not achieved in the presence of physiological levels of circulating estradiol in both subjects, being supraphysiological levels of estrogens required for basal serum FSH normalization (13, 14). This result is probably owing to the concomitant

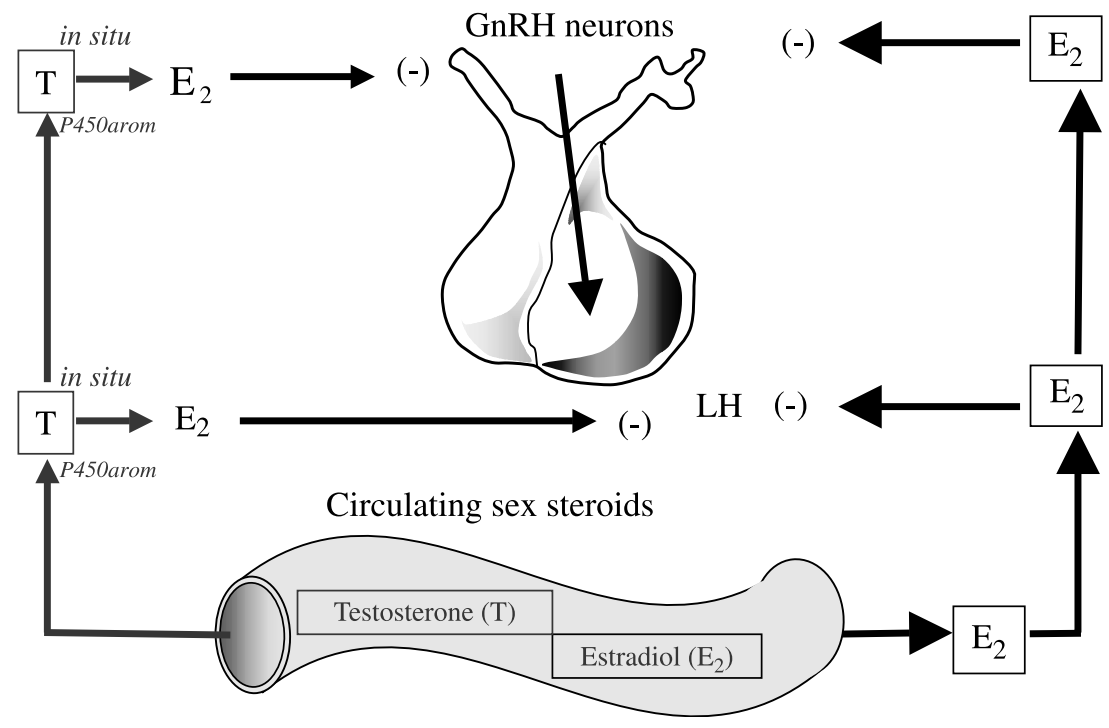

Figure 5 Mechanism of estrogen action at the pituitary and hypothalamic levels on gonadotropin feedback. Evidence for a key role of circulating estrogens. $\mathrm{GnRH}$, gonadotropin-releasing hormone; $\mathrm{LH}$, luteinizing hormone; P450arom, aromatase enzyme. 
severe impairment of spermatogenesis in our patient, a condition that also explains the finding of serum inhibin $\mathrm{B}$ below or at the lower limit of the normal range (34, 35). Interestingly, inhibin B and the inhibin B to FSH ratio were lower in subject 2 than in subject 1 according to a more severe pattern of spermatogenetic arrest revealed by the biopsy of the testis in subject 2 (11-14). Inhibin B, FSH, and the inhibin B to $\mathrm{FSH}$ ratio represent useful markers of impaired spermatogenesis $(35,36)$ and their significance for the evaluation of the functioning of the HPG axis is compromised when spermatogenesis is disrupted (37). Thus, even in this rare case of severe estrogen deficiency, the impairment of spermatogenesis does not compromise the response of FSH to changes in circulating sex steroids, as in infertile men (37), while the inhibin B was more related to the spermatogenetic damage rather than to hormonal changes.

The analysis of the hormonal data of these two patients permits us to make some speculations about a putative role of estrogens in the maturation of hypothalamic function. Interestingly, both serum LH and FSH, even if higher than normal values, seem to be inappropriately lower if we consider them with respect to testosterone serum levels and the abnormal spermatogenesis, even in the presence of normal serum estradiol in phase 2 (Table 2). In fact, testosterone is below the normal range in subject 2 and FSH does not exceed the value of $11 \mathrm{IU} / \mathrm{l}$; these patterns are different to those related to the severe dysfunction of spermatogenesis in the presence of an intact hypothalamic-pituitary function $(34,37)$. This observation shares some analogy with previous results concerning hypothalamic-pituitary function in which a putative role of estrogens on the maturation of hypothalamic-pituitary function, as far as $\mathrm{GH}$, prolactin, and TSH secretion are concerned, was suggested on the basis of a decreased sensitivity of the GH/insulin-like growth factor-I axis to provocative stimuli in congenital aromatase deficiency (15). A partial insensitivity of the hypothalamic-pituitary unit could also involve the HPG axis in men with aromatase deficiency, accounting for the discrepancy between the clinical condition of hypogonadism (hypotestosteronemia and impaired spermatogenesis) and the only slightly elevated levels of basal gonadotropins. This discrepancy is present also in the other two aromatase-deficient men described in the literature (12, 27-29). Evidence of a conspicuous reservoir of gonadotropins in the pituitary cells, as confirmed by the exaggerated response to GnRH administration (reflecting pituitary sensitivity to GnRH) even in the absence of circulating estrogens (phase 1, Fig. 2), goes on the direction of a possible involvement of estrogens in hypothalamic maturation and function. In rodents, estrogen modulates its own biological actions at different levels of the male reproductive axis throughout the lifespan by acting on pituitary and hypothalamic estrogen receptor (ER $\alpha$ and
ER $\beta$ ) gene expression (38). Estrogens probably promote the functional maturation of the hypothalamus and pituitary from the first step of structural development in rodents, particularly at puberty $(39,40)$. Thus, it could not be excluded that, in men, estrogen exposure during the fetal period and throughout life may constitute a prerequisite for a normal functioning of the HPG axis, as in rodents $(39,40)$ and male rhesus monkeys $(41)$ in which early exposure to estrogens guarantees an appropriate sensitization and a normal functioning of the HPG axis during adulthood. Thus, an intact feedback of both gonadotropins probably needs normal aromatase functioning and/or an adequate circulating amount of estrogens acting on hypothalamus. In this view, it is possible that this maturative mechanism fails in men with congenital estrogen deficiency and the absence of abnormalities of gonadotropin secretion and of testis size at birth (42) and in early puberty (43) in an aromatase-deficient boy suggests that the modulatory role of estrogens on hypothalamus-pituitary function could become effective only after childhood, at the time of puberty (an old concept called 'priming' by endocrinologists) (44), as for estrogen-related LH resurgence in male rhesus monkeys (41). Again, the congenital lack of estrogens during infancy and puberty could compromise the integrity of the HPG axis as a consequence of chronic severe estrogen deprivation. It should be remarked that congenital estrogen deficiency implies a severe estrogen depletion also during fetal life, thus, early development and maturation of the hypothalamus may be compromised (45) as well as the masculinization of hypothalamus, a process that involves $\mathrm{GnRH}$ neurons $(45,46)$ and hypothalamic structures $(47,48)$. Recently, a pivotal role of estradiol in HPG and pituitary maturation has been postulated in rodents $(40,49)$. Anyhow, the modulation and the control of gonadotropin secretion by estrogens in men as well as its role as a 'primer' during fetal life, early infancy, and childhood remain a matter of debate, since the operating molecular mechanisms at hypothalamic and pituitary levels are unknown. It remains to be ascertained, in fact, what the target cells (GnRH neurons, glia cells etc) of estrogens at hypothalamic level are and what the receptors (ER- $\alpha$, Er- $\beta$, non genomic pathway) involved in signal transduction are. At present, we know that estradiol might modulate the number and the function of GnRH receptors in the pituitary gland $(46,50,51)$, although no estrogen receptors (at least of the $\alpha$ type) were found in $\mathrm{GnRH}$ secreting neurons in monkeys (52). However, ER $\beta$ was found on GnRH-expressing neurons in male and female rats (53). A possible direct effect of estrogens on the central nervous system is supported by the improvement of sexual behavior observed in the first aromatasedeficient subject treated with estradiol $(48,54)$, and in the other with concomitant hypogonadism, treated with a combined therapy of estradiol and testosterone (55). 


\section{Conclusions}

The present study, coupling the outcomes coming from basal, GnRH stimulated and the pulsatile evaluation of LH and FSH secretion in two aromatase-deficient men, demonstrates that circulating estrogens play an inhibitory control in the feedback of LH by acting in the hypothalamus and the pituitary gland of men.

Further research will establish the relative influence of the local, and the circulating, production of estrogens, the molecular mechanism (ER-receptors or non genomic pathways) of the inhibitory feedback of LH, and FSH in men and try to identify the target cells of estrogens within the hypothalamus.

The discrepancy among testosterone serum levels, the arrest of spermatogenesis, and a slightly inappropriate increase in serum FSH (lower than expected) suggests a possible role of estrogens on that mechanism called in the past 'priming' (a sex steroid-dependent maturation) of the HPG axis in men, an event that probably never occurred in these two aromatase-deficient subjects as a consequence of chronic estrogen deprivation starting during fetal life.

\section{Acknowledgements}

We are indebted to Dr ssa Rossi Giuseppina (Department of Medicine and Medical Specialties) for technical support. Grant: Supported by grant from Ministero dell'Università e della Ricerca Scientifica (MURST, fondi ex 40\%).

\section{References}

1 Finkelstein JS, Whitcomb RW, O'Dea LS, Longcope C, Schoenfeld DA \& Crowley WF Jr. Sex steroid control of gonadotropin secretion in the human male. I. Effect of testosterone administration in normal and gonadotropin-releasing hormone-deficient men. Journal of Clinical Endocrinology and Metabolism 199173 609-620.

2 Finkelstein JS, O'Dea LS, Whitcomb RW \& Crowley WF. Sex steroid control of gonadotropin secretion in the human male. II. Effect of estradiol administration in normal and gonadotropin-releasing hormone-deficient men. Journal of Clinical Endocrinology and Metabolism 199173 621-628.

3 Bagatell CJ, Dahl KD \& Bremner WJ. The direct pituitary effect of testosterone to inhibit gonadotropin secretion in men is partially mediated by aromatization to estradiol. Journal of Andrology 1994 15 15-21.

4 Veldhuis JD \& Dufau ML. Estradiol modulates the pulsatile secretion of biologically active luteinizing hormone in man. Journal of Clinical Investigation 198780 631-638.

5 Schnorr JA, Bray MJ \& Veldhuis JD. Aromatization mediates testosterone's short-term feedback restraint of 24-h endogenously driven and acute exogenous gonadotropin-releasing hormonestimulated luteinizing hormone and follicle-stimulating hormone secretion in young men. Journal of Clinical Endocrinology and Metabolism 200186 2600-2606.

6 Hayes FJ, Seminara SB, Decruz S, Boepple PA \& Crowley WF, Jr. Aromatase inhibition in the human male reveals a hypothalamic site of estrogen feedback. Journal of Clinical Endocrinology and Metabolism 200085 3027-3035.
7 Mauras N, O'Brien KO, Klein KO \& Hayes V. Estrogen suppression in males: metabolic effects. Journal of Clinical Endocrinology and Metabolism 200085 2370-2377.

8 Wickman S \& Dunkel L. Inhibition of P450 aromatase enhances gonadotropin secretion in early and midpubertal boys: evidence for a pituitary site of action of endogenous E. Journal of Clinical Endocrinology and Metabolism 200186 4887-4894.

9 Taxel P, Kennedy DG, Fall PM, Willard AK, Clive JM \& Raisz LG. The effect of aromatase inhibition on sex steroids, gonadotropins, and markers of bone turnover in older men. Journal of Clinical Endocrinology and Metabolism 200186 2869-2874.

10 Leder BZ, Rohrer JL, Rubin SD, Gallo J \& Longcope C. Effects of aromatase inhibition in elderly men with low or borderline-low serum testosterone levels. Journal of Clinical Endocrinology and Metabolism 200489 1174-1180.

11 Faustini-Fustini M, Rochira V \& Carani C. Oestrogen deficiency in men: where are we today? European Journal of Endocrinology 1999 $140111-129$.

12 Rochira V, Balestrieri A, Madeo B, Spaggiari A \& Carani C. Congenital estrogen deficiency in men: a new syndrome with different phenotypes; clinical and therapeutic implications in men. Molecular and Cellular Endocrinology 2002193 19-28.

13 Carani C, Qin K, Simoni M, Faustini-Fustini M, Serpente S, Boyd J, Korach KS \& Simpson ER. Effect of testosterone and estradiol in a man with aromatase deficiency. New England Journal of Medicine 1997337 91-95.

14 Maffei L, Murata Y, Rochira V, Tubert G, Aranda C, Vazquez M, Clyne CD, Davis S, Simpson ER \& Carani C. Dysmetabolic syndrome in a man with a novel mutation of the aromatase gene: effects of testosterone, alendronate, and estradiol treatment. Journal of Clinical Endocrinology and Metabolism 200489 61-70.

15 Rochira V, Balestrieri A, Faustini-Fustini M, Borgato S, BeckPeccoz P \& Carani C. Pituitary function in a man with congenital aromatase deficiency: effect of different doses of transdermal estradiol on basal and stimulated pituitary hormones. Journal of Clinical Endocrinology and Metabolism 200287 2857-2862.

16 Smith EP, Boyd J, Frank GR, Takahashi H, Cohen RM, Specker B, Williams TC, Lubahn DB \& Korach KS. Estrogen resistance caused by a mutation in the estrogen-receptor gene in a man. New England Journal of Medicine 1994331 1056-1061.

17 Vanderschueren D \& Bouillon R. Editorial: estrogen deficiency in men is a challenge for both the hypothalamus and pituitary. Journal of Clinical Endocrinology and Metabolism 200085 3024-3026.

18 Rochira V, Faustini-Fustini M, Balestrieri A \& Carani C. Estrogen replacement therapy in a man with congenital aromatase deficiency: effects of different doses of transdermal estradiol on bone mineral density and hormonal parameters. Journal of Clinical Endocrinology and Metabolism 200085 1841-1845.

19 Genazzani AD, Petraglia F, Benatti R, Montanini V, Algeri I, Volpe A \& Genazzani AR. LH secretory burst duration is independent from LH, prolactin or gonadal steroid plasma levels in amennorheic women. Journal of Clinical Endocrinology and Metabolism 199172 1220-1225.

20 Oerter KE, Guardabasso V \& Rodbard D. Detection and characterization of peaks and estimation of instantaneous secretory rate for episodic pulsatile hormone secretion. Computers and Biomedical Research 198619 170-191.

21 Genazzani AD \& Rodbard D. Evaluation of methods for detection of pulsatile hormone secretion: sensitivity vs specificity. Acta Endocrinologica (Copenhagen) 1991124 295-306.

22 Thorner MO, Vance ML, Laws ER Jr, Horvath E \& Kovacs K. The anterior pituitary. In Williams Textbook of Endocrinology, 9th edn, ch 9, pp 249-340. Eds JD Wilson, DW Foster, HM Kronenberg \& PR Larsen. Philadelphia, PA: WB Saunders Co, 1998.

23 Wu FCW, Taylor PL \& Sellar RE. LHRH pulse frequency in normal and infertile men. Journal of Endocrinology 1989123 149-158.

24 Santen RJ \& Bardin CW. Episodic lutinizing hormone secretion in man. Pulse analysis, clinical interpretation, physiologic mechanisms. Journal of Clinical Investigation 197352 2617-2628. 
25 De Martino MU, Pastore R, Caprio M, Frajese G \& Fabbri A. Dynamic testing in the evaluation of male gonadal function. Journal of Endocrinological Investigation 200326 107-113.

26 Morishima A, Grumbach MM, Simpson ER, Fisher C \& Qin K. Aromatase deficiency in male and female siblings caused by a novel mutation and the physiological role of estrogens. Journal of Clinical Endocrinology and Metabolism $1995803689-3698$.

27 Bilezikian JP, Morishima A, Bell J \& Grumbach MM. Increased bone mass as a result of estrogen therapy in a man with aromatase deficiency. New England Journal of Medicine 1998339 599-603.

28 Herrman BL, Saller B, Janssen OE, Gocke P, Bockish A, Sperling H, Mann K \& Broecker M. Impact of estrogen replacement therapy in a male with congenital aromatase deficiency caused by a novel mutation in the CYP19 gene. Journal of Clinical Endocrinology and Metabolism 200287 5476-5484.

29 Rochira V, Granata ARM, Madeo B, Zirilli L, Rossi G \& Carani C. Estrogens in males: what have we learned in the last 10 years? Asian Journal of Andrology 20057 3-20.

30 Genazzani AD, Forti G, Maggi M, Milloni M, Cianfanelli F, Guardabasso V, Toscano V, Serio M \& Rodbard D. Pulsatile secretion of LH in agonadal men before and during testosterone replacement therapy. Journal of Endocrinological Investigation 1990 10 777-786.

31 van Bergeijk L, Gooren LJG, van Kessel H \& Sassen AM. Effects of continuous LHRH infusion on plasma levels of LH and FSH in males, before and after oestrogen or anti-oestrogen treatment. Hormone and Metabolic Research 198618 558-564.

32 Shozu M, Sebastian S, Takayama K, Hsu WT, Schultz RA, Neely K, Bryant M \& Bulun SE. Estrogen excess associated with novel gainof-function mutations affecting the aromatase gene. New England Journal of Medicine $2003 \mathbf{3 4 8} 1855-1865$.

33 Hayes FJ, Decruz S, Seminara SB, Boepple PA \& Crowley WF, Jr. Differential regulation of gonadotropin secretion by testosterone in the human male: absence of a negative feedback effect of testosterone on follicle-stimulating hormone secretion. Journal of Clinical Endocrinology and Metabolism 2001 86 53-58.

34 Griffin JE \& Wilson JD. Disorders of the testes and the male reproductive tract. In Williams Textbook of Endocrinology, 10th edn, pp 706-769. Eds PR Larsen, HM Kronenberg, S Melmed \& KS Polonsky. Philadelphia, PA: Saunders, 2003.

35 Von Eckardstein S, Simoni M, Bergmann M, Weinbauer GF, Gassner P, Shepers AG \& Nieschlag E. Serum inhibin B in combination with serum follicle-stimulating hormone (FSH) is a more sensitive marker than serum FSH alone for impaired spermatogenesis in men, but cannot predict the presence of sperm in testicular tissue samples. Journal of Clinical Endocrinology and Metabolism $1999 \mathbf{8 4} 2496-2501$.

36 Andersson AM, Petersen JH, Jørgensen N, Jensen TK \& Skakkebæk NE. Serum inhibin B and follicle-stimulating hormone levels as tools in the evaluation of infertile men: significance of adequate reference values from proven fertile men. Journal of Clinical Endocrinology and Metabolism $2004892873-2879$.

37 Meachem SJ, Nieschlag E \& Simoni S. Inhibin B in male reproduction: pathophysiology and clinical relevance. European Journal of Endocrinology 2001145 561-571.

38 Tena-Sempere M, Gonzalez LC, Pinilla L, Huhtaniemi I \& Aguilar E. Neonatal imprinting and regulation of estrogen receptor alpha and beta mRNA expression by estrogen in the pituitary and hypothalamus of the male rat. Neuroendocrinology 200173 12-25.

39 Sanchez-Criado JE, Bellido C, Aguilar R \& Garrido-Gracia JC. A paradoxical inhibitory effect of oestradiol-17beta on GnRH selfpriming in pituitaries from tamoxifen-treated rats. Journal of Endocrinology $2005 \mathbf{1 8 6}$ 43-49.

40 Matagne V, Rasier G, Lebrethon MC, Gérard A \& Bourguignon JP. Estradiol stimulation of pulsatile gonadotropin-releasing hormone secretion in vitro: correlation with perinatal exposure to sex steroids and induction of sexual precocity in vivo. Endocrinology $20041452775-2783$.

41 Fraser MO, Arslan M \& Plant AM. Androgen and estrogen treatment, alone or in combination, differentially influences bone maturation, and hypothalamic mechanisms that time puberty in the male rhesus monkey (Macaca mulatta). Pediatric Research 200557 141-148.

42 Deladoëy J, Flück C, Bex M, Yoshimura N, Harada N \& Mullis PE. Aromatase deficiency caused by a novel P450arom gene mutation: impact of absent estrogen production on serum gonadotropin concentration in a boy. Journal of Clinical Endocrinology and Metabolism $1999 \mathbf{8 4} 4050-4054$.

43 Bouillon R, Bex M, Vanderschueren D \& Boonen S. Estrogens are essential for male pubertal periosteal bone expansion. Journal of Clinical Endocrinology and Metabolism $2004896025-6029$.

44 Plant TM. Puberty in primates. In The Physiology of Reproduction, The Physiology of Reproduction, 2nd edn, vol 2, pp 453-485. Eds E Knobil \& JD Neill. New York: Raven Press, 1994.

45 Quigley CA. The androgen receptor: physiology and pathophisiology. In Testosterone: Action-Deficiency-Substitution, 2nd edn, pp 33-106. Eds E Nieschlag \& HM Behre. Philadelphia, PA: Springer, 1998.

46 Herbison AE. Multimodal influence of estrogen upon gonadotropin-releasing hormone neurons. Endocrine Reviews 199819 302-330.

47 Swaab DF. The complex effects of sex hormones on the brain it all depends on the species, sex, age and cell type. XX versus XY 2003 $13-4$.

48 Carani C, Rochira V, Faustini-Fustini M, Balestrieri A \& Granata ARM. Role of estrogen in male sexual behaviour: insights from the natural model of aromatase deficiency. Clinical Endocrinology 199951 517-524.

49 Nwagwu MO, Baines H, Kerr JB \& Ebling FJ. Neonatal androgenization of hypogonadal (hpg) male mice does not abolish estradiol-induced FSH production and spermatogenesis. Reproductive Biology and Endocrinology 2005348.

50 Mc Ardle CA, Schomerus E, Gröner I \& Poch A. Estradiol regulates gonadotropin-releasing hormone receptor number, growth and inositol phosphate production in a T3-1 cells. Molecular and Cellular Endocrinology 199287 95-103.

51 Kaiser UB, Conn PM \& Chin WW. Studies of gonadotropinreleasing hormone (GnRH) action using $\mathrm{GnRH}$ receptor-expressing pituitary cell lines. Endocrine Reviews 199718 46-70.

52 Sullivan KA, Witkin JW, Ferin M \& Silverman AJ. Gonadotropinreleasing hormone neurons in the rhesus macaque are not immunoreactive for the estrogen receptor. Brain Research 1995 685 198-200.

53 Hrabovszky E, Steinhauser A, Barabas K, Shughrue PJ, Petersen SL, Merchenthaler I \& Liposits Z. Estrogen receptor-beta immunoreactivity in luteinizing hormone-releasing hormone neurons of the rat brain. Endocrinology $20011423261-3264$.

54 Rochira V, Balestrieri A, Madeo B, Baraldi E, Faustini-Fustini M, Granata AR \& Carani C. Congenital estrogen deficiency: in search of the estrogen role in human male reproduction. Molecular and Cellular Endocrinology $2001 \mathbf{1 7 8} 7-115$.

55 Carani C, Granata AR, Rochira V, Caffagni G, Aranda C, Antunez P \& Maffei LE. Sex steroids and sexual desire in a man with a novel mutation of aromatase gene and hypogonadism. Psychoneuroendocrinology $200530413-417$.

Received 13 April 2006

Accepted 14 July 2006 